\title{
CAN Dispositionalism ABOUT BELIEF VINDICATE DOXASTICISM ABOUT DELUSION?
}

\author{
JOSÉ EDUARDO PORCHER
}

\begin{abstract}
Clinical delusions have traditionally been characterized as beliefs in psychiatry. However, philosophers have recently engaged with the empirical literature and produced a number of objections to the so-called doxastic status of delusion, stemming mainly from the mismatch between the functional role of delusions and that expected of beliefs. In response to this, an appeal to dispositionalism about the nature of belief has been proposed to vindicate the doxastic status of delusion. In this paper, I first present the objections to attributing beliefs to delusional patients and the application of dispositionalism in the attempt to vindicate doxasticism. I then assess this application and some responses to the objections to the doxastic characterization. Finally, I offer some conclusions about the limits of folk-psychological concepts in the characterization and explanation of complex psychological phenomena such as delusions.
\end{abstract}

Keywords: Delusion; belief; folk psychology; dispositionalism; doxasticism.

\section{Introduction}

Delusions have traditionally been thought of as beliefs. Indeed, they are referred to as beliefs almost everywhere in the psychiatric literature, as exemplified by the latest edition of what is perhaps its most influential handbook, the Diagnostic and Statistical Manual of Mental Disorders (DSM-5). Here is its definition of delusion:

A false belief based on incorrect inference about external reality that is firmly sustained despite what almost everybody else believes and despite what constitutes incontrovertible and obvious proof or evidence to the contrary. (American Psychiatric Association 2013, p.819)

However, the implausibility of ascribing full-fledged belief to delusional subjects has been hinted at at least since the 1910s, when both Jaspers' General Psychopathology and Bleuler's Textbook of Psychiatry were published. The set of objections against the traditional view forms a conspicuous obstacle for doxastic accounts. ${ }^{1}$

\section{Lack of content}

The first objection-originally raised by Jaspers (1913/1963) and elaborated recently by Berrios (1991) and Sass (1994)—denies that delusions are contentful states.

Principia 19(3): 379-404 (2015).

Published by NEL — Epistemology and Logic Research Group, Federal University of Santa Catarina (UFSC), Brazil. 
One may call this the expressivist (Gerrans 2001) or non-assertoric (Young 1999) account. This view is motivated by the fact that most (if not all) delusions appear obviously false or incoherent. The aforementioned Cotard delusion is a prized example of proponents of this view. Berrios, for example, states that when a patient who utters a verbal formula such as 'I am dead' or 'My internal organs have been removed' is questioned as to the real meaning of these assertions, she will not be able to coherently discuss them or their implications. 'Properly described', says Berrios, 'delusions are empty speech-acts that disguise themselves as beliefs' (1996, p.126, my emphasis). 'Their so-called content refers neither to world, nor self'. 'Delusions are so unlike normal beliefs that it must be asked why we persist in calling them beliefs at all' (1996, p.114-5). A wide variety of other cases besides Cotard's can be summoned in favor of such a view. For example, an intermetamorphosis patient claimed that his mother changed into another person every time she put her glasses on (De Pauw and Szulecka 1988); another patient that had the delusion that there was a nuclear power station inside his body (David 1990); and yet another that had the delusion of being both in Boston and in Paris at once (Weinstein and Kahn 1955).

\section{Self-defeating content}

One may not want to deny that delusional states possess content, and still object that it is difficult to see how the delusional patient themselves could believe such content. Again, Cotard patients are a fitting example. Bermudez voices this concern in stating that there is 'something content-irrational about the belief ... that one is dead-because, to put it mildly, the belief is pragmatically self-defeating' (2001 p.479, my emphasis). Not only is it unclear that a self-defeating assertion such as 'I am dead' could be coherently expressed, the question is open whether there can be self-defeating beliefs to begin with (as opposed to mere verbal utterances).

\section{Lack of evidence}

A distinctly rationalist objection consists in pointing out that delusional subjects appear, as opposed to self-deceived ones, to lack reasons or evidence for their delusional state. However faulty the reasons or flimsy (and biased) the evidence one may have to support some self-deceptive belief, there will be nevertheless some kind of support for such a belief. In contrast with this, Campbell cites the well-known case of 'a patient who looked at a row of empty marble tables in a café and became convinced that the world was coming to an end' (2001, p.95). Notwithstanding the DSM definition of delusions (that they are held 'despite what constitutes incontrovertible and obvious proof or evidence to the contrary'), Campbell points out that it is difficult to understand (to put it mildly) how an experience of marble tables could verify the

Principia 19(3): 379-404 (2015). 
proposition 'The world is ending'. On the other hand, there is at any time a considerable body of evidence against the truth of the delusional content, to which the delusional subject seems utterly impervious. In turn, Egan (2009, p.266) observes that if we take a certain responsiveness to evidence as essential to belief, then we'll be reluctant to say that delusional subjects genuinely believe the content of their delusions. In other words, if there is a constitutive relationship between belief and evidence (even in the case of irrational belief and improper evidence), then it seems that delusional states do not warrant the ascription of delusional beliefs.

\section{Theoretical reasoning}

Many authors, such as Velleman (2000), take belief to be somehow aimed at truth. This may constitute an objection to the doxastic conception of delusion in a spirit similar to that of Gendler's (2007) objection to the doxastic conception of self-deception. It points to one of the ways in which delusional states present a degree of circumscription that speaks against their being properly taken as beliefs (Young 1999, p.581). Egan calls this property of delusional states inferential circumscription (2009, p.266). As Bayne and Pacherie neatly put it, proponents of such a view of belief point out that

A subject will normally accept the obvious logical implications of her beliefs-at least when these are pointed out to her. And when she realizes that some of her beliefs are inconsistent, she will normally engage in a process of revision to restore consistency. In contrast, deluded patients often fail to draw the obvious logical consequences of their delusions and show little interest in resolving apparent contradictions between their delusion and the rest of their beliefs. (2005, p.164)

This is the precisely the spirit of the following claim by Currie and Ravenscroft:

If someone says that he has discovered a kind of belief that is peculiar in that there is no obligation to resolve or even to be concerned about inconsistencies between these beliefs and beliefs of any other kind, then the correct response to him is to say that he is talking about something other than belief. (2002, p.176)

However, the majority of patients with the Capgras delusion, for example, do not draw the consequences the content of their delusion would usually mandate: their worldview does not seem to change at all as a consequence of supposedly adopting the belief that their spouses have been abducted and that the person they see in front of them is an impostor (Davies and Coltheart 2000). Whatever this state is, therefore, it seems that it is severely encapsulated, failing to be integrated with the subject's web of belief. But beliefs are the mainstay of theoretical and practical reasoning and, while

Principia 19(3): 379-404 (2015). 
one may ascribe false belief to subjects for any number of reasons, a state that fails to have the appropriate connections to the subject's other mental states may not be properly described as a belief. ${ }^{2}$ As exemplified by Currie and Ravenscroft, this view is especially espoused by authors who (tacitly or explicitly) endorse a consistency constraint on belief-ascription.

Indeed, authors such as Quine and Ullian (1970), as well as Fodor (1983), have argued that one of the attributes of a belief qua belief is its property of being inseparably connected with other beliefs of potentially widely diverse contents. Quine's answer as to why beliefs should be webbed or interconnected with other beliefs in a way that precludes severe encapsulation rests on the conditions of epistemic assessment of beliefs-for instance, whether I am warranted in believing that an acquaintance of mine lives in Chicago may depend on whether I believe that Chicago is a city and believe that cities are bigger than towns, etc. And for Quine, the conditions of epistemic assessment of beliefs are part of their functional role; beliefs are states or attitudes that are constituents in (what Fodor calls) the central processing that takes place in the mind. Thus, like-minded theorists will deny that delusional subjects are in the hold of belief.

\section{Practical reasoning}

Belief has profound connections to action, and many delusional subjects fail to act in ways expected of agents who really believed the content of their delusions. As Currie (2000, p.175) puts it, delusion exerts a powerful psychological force, absorbing inner mental resources, but it fails to engage behavior in the way that we would expect of genuine belief. This seems likely due to the inferential circumscription noted above. Egan calls this characteristic of delusional patients behavioral circumscription (2009, p.266). It was noted by Bleuler, who stated that his delusional patients 'rarely follow up the logic to act accordingly, as, for instance, to bark like a dog when they profess to be a dog. Although they may refuse to admit the truth, they behave as if the expression is only to be taken symbolically' (1916/1924). In the same manner, Capgras patients who (for all we can see) sincerely affirm 'This is not my wife' or 'My mother has been replaced by an impostor' do not as a consequence of this go looking for their missing loved ones, nor do they call the police to report the breaking and entering perpetrated by the person they claim to be an impostor.

\section{Lack of appropriate affect}

Finally, delusional patients often fail to exhibit the affective or emotional responses one would expect of a person who believes the content of her assertions (Sass 1994, p.23-4). We may call this affective circumscription, since what is observed is a failure

Principia 19(3): 379-404 (2015). 
of integration between the subjects' delusional state and their emotional lives. Capgras patients are more often than not unmoved by the fate of their relatives whom, according to the doxastic interpretation of this delusion, they believe to have been abducted (Davies and Coltheart 2000). Why don't they exhibit the affective responses which the relevant beliefs would lead us to expect?

The last four objections are different aspects of what Bortolotti terms bad integration. She observes that 'although it is possible for a belief system to have some internal tension, most philosophers resist the thought that subjects capable of having beliefs can have dissonant attitudes simultaneously activated and operative at the forefront of their minds' (2010, p.62). In other words, delusions lack the holistic character expected of beliefs and do not respect the notion of a coherent belief system whose adjustments to one belief implies adjustments to many others (Young 2000, p.49). Belief-ascription in the context of delusion, then, is only admissible after explaining away these disparities between the roles that delusional states play in the overall cognitive economy of delusional patients and those roles we expect beliefs to play (following either folk-psychological intuitions or fully articulated theories of belief).

\section{A dispositional approach to delusion}

Having briefly introduced the concept of delusion and the problems faced by doxastic explanations, I now turn to the main purpose of this paper, which is to examine the tenability of a dispositional account of delusional belief. Instead of giving up doxasticism altogether in favor of an alternative characterization, such as Currie's and Ravenscroft's (2002) metacognitive account, which relies on propositional imagination rather than belief, the strategy I will rehearse consists in presenting a non-standard account of belief, and trying to show that deluded subjects meet the criteria it proposes for being in a belief-state. My starting point will be an overview of the dispositionalist theory of belief proposed by Schwitzgebel (2001; 2002), to then explore its subsequent appropriation in the literature on delusions by Bayne and Pacherie (2005).

\subsection{In-between believing and not believing}

H.H. Price, in his famous series of lectures on belief, discussed the not uncommon phenomenon wherein a person may systematically feel himself to be and act as if he were fully committed to $p$ in one set of circumstances, while systematically feeling and acting as if the opposite were true in others. He called this 'half-belief' (1960/1969, p.302-14). More recently, Schwitzgebel (2001) recognized that there

Principia 19(3): 379-404 (2015). 
are countless cases in which a simple yes or no answer to the question 'Does $S$ believe that $p$ ?' doesn't seem to be available, and that they can have a wide variety of causes. From these cases, Schwitzgebel draws the following conclusion:

For any proposition $p$, it may sometimes occur that a person is not quite accurately describable as believing that $p$, nor quite accurately describable as failing to believe that $p$. Such a person, I will say, is in an 'in-between state of belief' (2001, p.76).

By way of illustration, he offers three examples stemming from three different causes, which are neither meant nor thought to be exhaustive. The first is gradual forgetting. It concerns the ubiquitous case in which someone forgets, say, an old colleague's last name. Years ago, you knew your colleague's full name. Now, you can only remember his first name (and, perhaps, the first letter of his last name). Years from now, you probably won't remember his name at all. So the belief that your colleague's name was Konstantin Guericke was fully present when you were in college, and will be fully absent when you are eighty years old. The question then is, what is the state you're in right now? Schwitzgebel asks: 'is it plausible to think that in the years between there was a discrete moment before which I absolutely had this belief and after which I absolutely did not? At some point during the course of forgetting, I must be between believing and failing to believe that his last name is 'Guericke' (or whatever)' (2001, p.77). Arguably, we spend most of our lives in such in-between states.

His second example is derived from our failure to think things through. Think of a school teacher who mentions prime numbers in her lessons, correctly listing the lower primes 2, 3, 5, 7, 11 etc. Now, when she is asked about or decides to offer the definition of 'prime number', she typically says that a prime number is any positive integer that can be divided evenly only by 1 and itself. This definition is not correct, however, since the number 1 is a positive integer evenly divisible only by 1 and itself, but it is not a prime number. On the other hand, if you asked the school teacher if 1 is a prime she would promptly answer that it isn't. So now the question is, does she believe that all positive integers which are evenly divisible only by themselves and 1 are prime? We have reasons to answer in the affirmative, for instance, she would never list 1 as a prime number. But we also have reasons to answer in the negative, for instance, the occasions on which she would be disposed to offer a correct definition of primes are few. For this reason, Schwitzgebel claims that the most careful and accurate description would requires us to withhold the attribution of a belief.

Finally, there is variability with context and mood. Here, Schwitzgebel evokes a familiar example in the same vein as Price's famous case of the half-believing theist. Price suggests the case of someone who on Sundays bears all the subjective and objective marks of someone who believes that there is a God, but who on weekdays bears none of them. Schwitzgebel, on the other hand, suggests the case of someone 
who, in certain moods and in certain contexts, bears all the subjective and objective marks, and who, in other moods and contexts, doesn't. (The latter spectrum may include circumstances from those of weakened confidence, as when someone thinks of God as 'a beautiful metaphor', to those where confidence is removed completely from recognition or memory.) Though he may be a regular Sunday churchgoer, he does not feel the urge to defend himself or his religion when, for example, his atheistic friends mock religious belief. In fact, at such moments (especially on weekdays), he may even find himself mildly convinced of the incongruousness of theistic dogma. How can we decide, then, whether he believes that God exists? The point is that a simple yes or no answer would be misleading. Thus, the widespread presence of problematic circumstances for belief-ascription such as these encourages the development of an account of belief that allows us to talk intelligibly about such in-between states-that allows us to say more than just that the subject 'sort of' believes something.

\subsection{Schwitzgebel's dispositional account of belief}

Given the conviction that there is a continuum ranging from complete absence to complete presence of any given belief, a probabilistic treatment might be thought to manage cases of in-between believing. According to such an account, a person's beliefs would be characterized by a degree of confidence ranging from 0 (i.e. absolute confidence in the falsity of $p$ ) to 1 (i.e. absolute confidence in the truth of $p$ ), with 0.5 in between-perhaps representing suspension of judgment or a state of skeptical doubt. Such an approach may be thought to account for at least some of the cases because we could assign our half-believing theist, for example, with a degree of confidence of 0.7 or 0.8 . However, this would consist in a gross oversimplification of the kind of uncertainty or wavering present in the cases discussed. The school teacher and the half-believing theist cannot be properly described as simply fluctuating between different degrees of confidence, since they are, 'at a single time, disposed quite confidently to assert one thing in one sort of situation and to assert its opposite in another' (Schwitzgebel 2001, p.79). Nor can the process of gradually forgetting someone's last name be properly translated into a slow decline in one's confidence in the truth of some proposition. A purely probabilistic approach fails to capture the vast array of detail present in these cases.

Furthermore, it would seem that traditional representational accounts of belief cannot provide a way of successfully dealing with in-between belief states either. Indeed, to suggest that someone is in an in-between representational state appears even more unnatural than the probabilistic strategy would have it. Most talk of belief as representation makes out belief to be a categorical state-having a belief that $p$ is something like having the sentence $p$ inscribed in one's 'belief box' in the language of thought, according to one popular account. The metaphor must be pushed, though,

Principia 19(3): 379-404 (2015). 
if representationalists wish to embrace the very plausible presence of halfway states. Schwitzgebel points out that for that, however, they risk making a caricature of their own account by incorporating, say, explanations of gradual forgetting in terms of a sentence slowly 'losing its color', etc. To avoid the far-fetched claim that sentences either are or aren't inscribed in the belief box, then, Schwitzgebel opts for pursuing a more flexible explanation of the nature of belief and belief-ascription by appeal to a revision of Ryle's dispositionalism. Ryle argued that to believe something is simply to be disposed to do and feel certain things in appropriate situations. To use his own example, to believe that the ice you're skating on is dangerously thin is, in his words:

[T]o be unhesitant in telling oneself and others that it is thin, in acquiescing in other people's assertions to that effect, in objecting to statements to the contrary, in drawing consequences from the original proposition, and so forth. But it is also to be prone to skate warily, to shudder, to dwell in imagination on possible disasters and to warn other skaters. It is a propensity not only to make certain theoretical moves but also to make certain executive and imaginative moves as well as to have certain feelings. (1949, p.134-5)

A person who has the dispositions described in Ryle's example matches what Schwitzgebel calls a dispositional stereotype. By a stereotype, he means a cluster of properties we are apt to associate with something-be it an object, a class, or a property. An example he adapts from Putnam (1975) is that of the stereotype of a tiger, whose properties include being striped and having four legs, among others. ${ }^{3}$ This doesn't mean, of course, that a three-legged tiger without stripes is not a tiger. It only means that such a tiger wouldn't be a stereotypical one. Furthermore, the accuracy of stereotypes varies greatly in degree, so that the more or less objects instantiate their stereotypical properties, the more or less accurate the stereotype will be.

Schwitzgebel characterizes dispositions by means of conditional statements of the form 'If condition $\mathrm{C}$ holds, then object $\mathrm{O}$ will (or is likely to) enter (or remain in) state $S^{\prime}$ (2002, p.250). ${ }^{4}$ O's entering $S$ is the manifestation of a disposition, whereas $C$ is the condition of manifestation, and the event of C's obtaining is the trigger. Therefore, $\mathrm{O}$ will have the relevant disposition if and only if the corresponding conditional statement is true. Thus we may speak of dogs having the disposition to wag their tails when excited because when they are excited (the trigger), they wag their tails (the manifestation).

A dispositional stereotype is simply a stereotype whose elements are dispositional properties. Many familiar stereotypes are dispositional, such as personality traits. For example, being impulsive is (something like) being disposed to act without thinking things through; being sympathetic is (something like) being disposed to easily putting oneself in someone else's position; etc. Just like having a personality trait is matching a stereotype, Schwitzgebel claims, so too is having a belief. As a consequence, 
the list of dispositions associated with a given belief is as indefinite as that of having a particular personality trait, and won't be linked to it explicitly by a conscious effort. The most fruitful way of thinking about dispositional stereotypes is, rather, as consisting of clusters of dispositional properties (which we associate with particular stereotypes). In turn, with regard to the different kinds of dispositions belonging specifically to the stereotype of belief (for instance, the belief that there is beer in the fridge), Schwitzgebel identifies three main categories:

The most obvious, perhaps, are behavioral dispositions, the manifestations of which are verbal and nonverbal behavior, such as, in the present case, the disposition to say that there is beer in the fridge (in appropriate circumstances) and the disposition to go to the fridge (if one wants a beer). Equally important, though rarely invoked in dispositional accounts of any sort, are what may be called phenomenal dispositions, dispositions to have certain sorts of conscious experiences. The disposition to say silently to oneself, 'there's beer in my fridge', and the disposition to feel surprise should one open the fridge and find no beer are phenomenal dispositions stereotypical of the belief that there is beer in the fridge. Finally, there are dispositions to enter mental states that are not wholly characterizable phenomenally, such as dispositions to draw conclusions entailed by the belief in question or to acquire new desires or habits consonant with the belief. Call these cognitive dispositions. (2002, p.252)

In Schwitzgebel's dispositionalism, a person who possesses all the dispositions in the stereotype for belief that $p$ will always accurately be described as believing that $p$. On the other hand, a person who possesses none of those dispositions will never accurately be so described. What is especially relevant to the present investigation, of course, are the cases in between those extremes-cases which, in all probability, account for most of our beliefs. As we have seen, those cases include gradual learning and forgetting and ignorance of related details, but also self-deception and, perhaps, even some cases of delusion. That is, cases where some but not all of the dispositions in a stereotype are present, and which help illustrate that having a disposition is not something which can always be ascribed in black-and-white terms. The core idea of this view with respect to belief, then, is that

To believe that $p \ldots$ is nothing more than to match to an appropriate degree and in appropriate respects the dispositional stereotype for believing that $p$. What respects and degrees of match are to count as 'appropriate' will vary contextually and so must be left as a matter of judgment. (2002, p.253)

The ability of such a view of belief to handle the gray area of ascription is made clear by the postulate that no single disposition is either necessary nor sufficient for the possession of any belief (since dispositionalism links belief-ascription to clusters of dispositions). Schwitzgebel avoids the inflexibility of traditional accounts by 
admitting vagueness and context-dependency as integral to belief-ascription. As opposed to features that would entail undermining the value of ascription, they are supposed to provide the margin of safety we as belief ascribers need. Finally, the problem Schwitzgebel intends to deal with is fundamentally the same we face when trying to ascribe belief to delusional patients, namely, that there are particular subjects of whom there is reason to think that they believe $p$ but also reason to think that they do not believe $p$ (or even that they believe $\neg p$ ).

\subsection{Bayne's and Pacherie's appropriation}

Bayne and Pacherie (2005) provide an attempt at restoring our ability, in the face of the reviewed objections and of alternative accounts, to make belief-ascriptions when talking about deluded subjects. As a motivation, they cite matters of practical importance such as the implications that theoretical speculation has for the treatment of delusions. They refer to cognitive behavioral therapy (CBT), an important form of therapy for delusions (Dickerson 2000), one of the essential components of which involves questioning the consistency and plausibility of the patient's delusions (Chadwick, Brichwood and Trower 1996). This form of therapy, they argue, seems to accord with the doxastic account, in that the therapist treats the delusional patient as a believer of $p$ and gently invites the patient to question the delusional belief.

Granted the important point that a sound methodology for the development of philosophical theories of the human mind should carefully attend to its compatibility with the relevant empirical data, the focus of my interest in their defense of doxasticism lies especially in their sketch of a theory of belief that, according to them, can elude the usual objections. In order to establish that at least some delusions qualify as beliefs they turn to Cherniak (1986) and Schwitzgebel (2002) for support. From Cherniak's account of 'minimal rationality' they derive the claim that the link between rationality and belief-ascription is much looser than classical theories of belief-ascription generally allow. Interpretationism - the view that we can gain an understanding of the nature of the mental by reflecting on the nature of interpretation, the process of ascribing propositional attitudes to an individual on the basis of what she says and does-is one such theory. It endorses a general rationality constraint that has been widely supported in the philosophical literature:

When we are not [rational], the cases defy description in ordinary terms of belief and desire. (Dennett 1987, p.87)

If we are intelligibly to attribute attitudes and beliefs, or usefully to describe motions as behavior, then we are committed to finding, in the pattern of behavior, belief, and desire, a large degree of rationality and consistency. (Davidson 1974, p.50)

Principia 19(3): 379-404 (2015). 
If we were to accept this, it would follow that the difficulty we face in trying to explain and predict irrational behavior in intentional terms stems from the fact that irrational behavior does not support the ascription of intentional states with determinate content. Rationality would be emphasized to the exclusion of almost all other considerations. ${ }^{5}$ However, upon closer inspection, the use of the folk-psychological concept of 'belief' (to focus on the intentional state we are presently concerned with) indicates that its extension is not homogeneous at all. As we have already seen, there are lots of kinds of different mental states we are prepared to call 'belief'. Hence, Bayne and Pacherie observe, even if they are right in that considerations of rationality play an important role in belief-ascription, theories like interpretationism obscure the heterogeneity of the set of states apt to be considered beliefs. As Cherniak urged, rationality constraints on belief-ascription should not be derived from a model of ideal rationality. 'Given our finitary predicament - the computational, memory, and time limitations we are subject to - it is actually irrational for us to aspire to ideal rationality' (Bayne and Pacherie 2005, p.180). What this entails for the present discussion is that the cognitive attitudes of delusional patients are continuous with our ordinary beliefs-that is, there is no categorical difference between the abnormal mental states observed in delusions and the normal states that constitute our everyday cognitive economy. If this is right, it constitutes an important first step toward a vindication of doxasticism about delusions. More important to the present investigation, on the other hand, is Bayne's and Pacherie's appeal to Schwitzgebel's dispositional account of belief in order to explain away the delusional subject's failure to manifest their beliefs in normal ways. From Schwitzgebel they derive the claim that beliefs are context-dependent in a number of ways:

First, which dispositions are actualized is a function of several factors: (1) the way the long-term memory of the individual is structured, something that depends in turn both on the cognitive organization of the species and on the personal history of the individual, (2) the current external context, and (3) the current motivational and affective set of the individual. Second, beliefascription is also context-dependent. According to Schwitzgebel, we have dispositional stereotypes for beliefs, specific clusters of behavioral, cognitive, and phenomenal dispositions we associate with given beliefs and expect to be manifested in standard situations. We attribute to a subject full belief that $p$ if he conforms to the associated stereotype in standard situations and if his deviations from the stereotype are readily explainable or excusable by appeal to some non-standard feature of the situation in which they occur. When a deviation from the stereotype cannot be excused or explained in this way, whether or not the attributor ascribes the belief will depend on the context of the belief ascription and what her interests are. (2005, p.181, my emphasis)

Dispositionalism does look like a very promising way to ensure that young children, the forgetful, the negligent, the weak-willed, the self-deceived, and the deluded be 
ascribed beliefs, despite the lapses in thinking and behavior that sometimes pose a challenge to these ascriptions. It makes it easy to secure permission to use beliefascriptive language in our descriptions of these individuals. That is so because, for the dispositionalist, the question whether a subject should be ascribed the belief is not just a matter of whether she manifests enough of the dispositions in the relevant cluster but also of whether her not manifesting some of these dispositions can be satisfactorily excused or explained by reference to non-standard aspects of her situation. Therefore, if deluded subjects' failure to manifest their beliefs in normal ways is excusable or explainable, their deviation from the dispositional stereotype associated with the relevant beliefs ceases to be a hindrance to belief-ascription.

Nevertheless, Bayne's and Pacherie's claim that the difficulties for the doxastic account can be resolved if belief-ascriptions are context-dependent is by no means beyond dispute. I now turn to a critical assessment of their attempt to make use of Schwitzgebel's dispositionalism in order to rescue doxasticism from the previously discussed objections.

\section{Can dispositionalism vindicate doxasticism?}

Tumulty (2011) has been the first author to challenge Bayne's and Pacherie's appeal to dispositionalism as a way to defend the doxastic conception of delusions. The core of her strategy consists in highlighting two features of Schwitzgebel's dispositionalism that Bayne and Pacherie overlook and subsequently arguing that they can't use that view of belief to vindicate doxasticism. Tumulty claims that Bayne and Pacherie underemphasize Schwitzgebel's distinction between excused non-manifestations of dispositions and explained dispositional absences. In addition, she claims that they also underemphasize the no-further-fact clause in Schwitzgebel's account-that is, the observation that once a dispositional profile has been exhaustively specified, there is no further factual question as to whether or not a subject really believes a given proposition. Tumulty argues that dispositionalism is neither plausible nor distinctive without these points, and that these points clash with Bayne's and Pacherie's aims. In this section, I present some of Tumulty's points and assess whether they damage Bayne's and Pacherie's dispositionalist response to the objections discussed.

\subsection{Deviations, excuses, and explanations}

Bayne and Pacherie see explanations of manifestation-failures as the way to make room for ascriptions of belief in the context of delusions. However, Tumulty notes that they seem to miss Schwitzgebel's implicit distinction between excuses and explanations. Whereas an excuse elucidates why someone fails to manifest a disposi-

Principia 19(3): 379-404 (2015). 
tion while suggesting she in fact has the disposition, an explanation of an apparent manifestation-failure suggests not that a subject is inhibiting a manifestation of a disposition, but rather that the disposition in question is altogether absent. And, as we saw, such a subject is said to deviate from the dispositional profile for the relevant belief. It should be noted, however, that while we may seem to have evidence for the absence of a disposition whenever we observe a manifestation-failure, only a subset of those manifestation-failures are actually rooted in disposition-absences. Awareness of excusing conditions is necessary if one is not to incorrectly judge a subject to deviate from a dispositional stereotype she actually fits.

If we wish to use Schwitzgebel's dispositionalism in order to count delusions as beliefs, Tumulty suggests, we need to look for excuses for all the ways in which deluded subjects fail to look like ordinary believers with respect to the content of their delusions. Bayne and Pacherie (2005, p.185) cite a fear of involuntary commitment, for example, to account for the failure of some patients to act on their alleged beliefs. While this does look like an excuse in the required sense-some deluded subjects may know that acting on their beliefs might result in hospitalization-Tumulty is unswayed by the excessive generality of other non-standard situational features to which they appeal in their attempt to account for other typical failures to manifest belief-appropriate dispositions. If Bayne and Pacherie want to uphold a dispositionalist form of doxasticism, they must answer the question of whether delusional subjects are inhibiting dispositions or rather lack them entirely. As we have seen, many deluded subjects act (or fail to act) in ways that make it likely they lack one or more of the important dispositions in the stereotype for belief in the content of their delusion. Of course, many non-deluded subjects also deviate from dispositional stereotypes for beliefs that they attribute to themselves, or that others may be tempted to attribute to them. But on the dispositionalist view of belief, the option of deciding that a deviation is not important is left open, and that option may be available with respect to subjects suffering from mental illness and abnormal/maladaptive behavior, as well as with respect to normal subjects in the hold of irrational patterns of reasoning.

A dispositionalist about delusional belief may opt to argue that interpreters could decide that a particular deviation from the dispositional stereotype for a given delusion is relatively unimportant. That would preserve our ability to say that a patient really believes the content of her delusion. However, as Tumulty observes, that wouldn't preserve our ability to say that the sum total evidence of the patient's dispositions points toward her so believing, where her so believing is a fact over and above her having the dispositional profile she has: 'It only preserves our ability to refer to those dispositions without misleading our audience about them' (2011, p.613). Thus, while dispositionalism has the resources to generate the ascriptive claims Bayne and Pacherie want, it does so at the cost of not giving them the same weight they do.

Principia 19(3): 379-404 (2015). 


\subsection{Context-dependency}

As we have seen, Bayne and Pacherie appropriate Schwitzgebel's claim that beliefascription is context-dependent. In cases when a deviation cannot be readily excused or explained, 'whether or not the attributor ascribes the belief will depend on the context of the belief ascription and what her interests are' (2005, p.181). Tumulty questions the strength of this appeal as a way to achieve a robust vindication of doxasticism. To better understand her point we may briefly review the role of context in Schwitzgebel's account. In one of his examples he discusses

a child studying for a test [who] reads, 'The Pilgrims landed at Plymouth Rock in 1620,' and remembers this fact. She is a bit confused about what Pilgrims are, though: she is unsure whether they were religious refugees or warriors or American natives. (2002, p.257)

Clearly this child (call her Jane) doesn't fully fit the stereotype for believing that the Pilgrims landed on Plymouth Rock in 1620. She won't be disposed to infer, for example, that europeans landed at Plymouth Rock in 1620. In a case like this there doesn't seem to be any available excuse that would render the ascription of the relevant belief uncontroversial. What (if anything) will determine the way we describe Jane's state are the practical matters with which we are concerned, such as her 'likely performance on a history dates quiz' (Schwitzgebel 2002, p.257). The lesson to be drawn from this, Tumulty argues, is that the introduction of belief-ascriptive language doesn't add to the information already available from the observation of the given dispositional profile, but only refers to it in a convenient and perhaps helpful way. Therefore, attending to the context of belief-ascription makes itself necessary when attributors need to decide whether the use of ascriptive shorthand will be helpful to their audience. It is in this way that Schwitzgebel's dispositionalism provides us with means to end disputes about how to describe in-between cases such as Jane's.

In the most difficult cases for ascription, however, the communicative demands on the attributor may not successfully determine whether or not it is appropriate to describe the subject as believing the content of their self-deception, say, or of her delusion. Cases like these, in which the set of ascribable dispositions available to the interpreter is such a 'mixed bag', leave us only with the option of specification-that is, describing how the subject's dispositions conform to the stereotype for the belief in question and how they deviate from it. There will be times, then, when withholding the use of ascriptive language is going to be preferable so as not to mislead one's audience. Such cases are those in which the observable deviations raise questions regarding both the content of the subject's attitude, and the nature of the attitude itself. So if there is no way to decide whether something is determinately a case of belief, our move should be to allow some indeterminacy in our belief talk, for fear that we should abandon it altogether. This is where Tumulty's observations meet

Principia 19(3): 379-404 (2015). 
Schwitzgebel's recent remarks on how to handle delusional states-or at least those which defy ascriptive language and practice. He suggests that 'believes that p' should be treated as a vague predicate admitting of vague cases:

\begin{abstract}
In in-between cases of canonically vague predicates like 'tall', the appropriateness of ascribing the predicate varies contextually, and often the best approach is to refuse to either simply ascribe or simply deny the predicate but rather to specify more detail (e.g., 'well, he's five foot eleven inches'); so too, I would argue, in in-between cases of belief. (2012, p.15)
\end{abstract}

Bayne and Pacherie want context-dependency, however, to support the view that delusions are beliefs (or at least that some of them are), whereas all it can really offer us is a pragmatic license to talk about delusions as beliefs whenever this is not apt to mislead our intended audience, and whenever there is no better alternative. Therefore, dispositionalism cannot grant them a definitive victory over competing accounts. Besides, it is conceivable that among the many cases that defy belief-ascriptive language there might be some cases of delusion that imagining-ascriptive language is better suited to describe (even if in localized instances, for the benefit of particular audiences). The fact that belief-ascriptive shorthand caters to the context and interests of the ascribers defeats Bayne's and Pacherie's purpose of defending a full-blooded doxastic view of delusions by appeal to dispositionalism about belief.

\title{
3.3. Revisiting the objections to the doxastic account
}

Finally, in order to complete our assessment of Bayne's and Pacherie's dispositionalist approach to delusions, I now turn to presenting and discussing their answers to the objections to the doxastic account I presented above, which they separate into three classes: content-based, evidence-based, and commitment-based. Their answers to the first two families of objections do not depend on dispositionalism, but rather on the contention that their proponents exaggerate the connections between belief and logical possibility on the one hand, and between belief and evidence on the other.

The first and second objections presented earlier ('Lack of content' and 'Selfdefeating content') converge in holding that what is allegedly believed by delusional subjects clashes with the nature of belief, because believability is taken to imply that the content be meaningful and logically possible. While not all delusional contents raise this kind of objection, those of Cotard and other delusions do. To which Bayne and Pacherie respond first by suggesting that issues of belief-ascription are best approached via the question of predictive leverage rather than claims about logical possibility' (2005, p.182). Indeed, there seems to be no principled reason to deny that even the most bizarre delusions lack content only in the sense and to the extent that they are obviously false or incoherent. If 'I am dead' really were necessarily false

Principia 19(3): 379-404 (2015). 
or pragmatically self-defeating, a stronger case could be made. Bayne and Pacherie argue that it is neither, at least in a number of very common usages-for example, those in which dying does not mean ceasing to exist. For example, consider the following testimony by Esmé Weijun Wang, a writer responsible for what is perhaps the only extant first-person account of the experience of Cotard delusion (quoted with permission).

In the beginning of my own experience with Cotard's delusion, I woke my husband before sunup. Daphne, our dog, stirred, began thumping her papillon-mutt tail against the bedsheets. I'd been in my studio, but now I was shaking my husband, and I was crying with joy.

'I'm dead,' I said, 'and you're dead, and Daphne is dead, but now I get to do it over. Don't you see? I have a second chance. I can do better now.'

Chris said, gently, 'I think you're alive.'

But this statement, of course, meant nothing. It was his opinion, and I had my solid belief. I can state that the sky is green, but will you see it as such? I felt buoyant at the belief that I was getting a second chance in some kind of afterlife -U it caused me to be kinder, to be more generous. I wasn't irritated by problems with computer downloads. I was sweet to telemarketers. It was true that I was dead, but I believed it made sense to play-act normalcy, or rather, an improved version of normalcy, because of the additional belief that I was in an afterlife. According to the logic of my delusion, this afterlife was given to me because I hadn't done enough to show compassion in my "real" life; and though I was now dead, my death was also an optimistic opportunity. (Wang 2014)

Note that Wang's conviction that she was dead was not completely circumscribed (or at least not completely), since she also formed the coherent conviction that she was experiencing an afterlife-likely an abductive explanation of the unshakeable conviction (the fact) that, although dead, she remained a subject of experiences.

In turn, the third objection presented earlier ('Lack of evidence') views the absence of support for that which is allegedly believed as conflicting with the nature of belief. In fact, as we saw, delusions typically are held in the face of overwhelming evidence to the contrary. Bayne and Pacherie do not view this as a real problem for doxasticism, denying that there is a constitutive connection between belief and evidence. Work by a multitude of researchers has established the existence-indeed, the prevalence-of non-rational elements in belief-formation and maintenance, such as cognitive biases and motivation (Nisbett and Ross 1980; Cherniak 1986; Kunda 1990). They also point out that there seems to be no principled reason to deny the possibility of beliefs being formed as a consequence of brain damage (perhaps not directly). Also, many proponents of so-called bottom-up accounts of delusion claim that at least some delusions are grounded in evidence of a sort (Bayne and Pacherie

Principia 19(3): 379-404 (2015). 
2004). Such accounts suggest that first-person evidence-evidence gathered directly from one's own experience, as opposed to the views of other people or to general knowledge-is at the source of delusion-formation (Davies et al., 2001). It may be worth noting that at least some beliefs in articles of faith are based in what Bayne and Pacherie refer to as 'first-person evidence', which may be as flimsy as a 'sense' that something is true.

Finally, it is the fourth, fifth, and sixth objections presented earlier ('Theoretical reasoning', 'Practical reasoning', and 'Lack of appropriate affect') that Bayne and Pacherie respond to by invoking dispositionalism. These objections view the deluded subject's circumscribed rational, behavioral and affective responses as conflicting with the nature of belief. In the context of dispositionalism, the set of commitmentbased objections can be thought of as asserting that delusional subjects who seem to believe that $p$ deviate so much from the dispositional profile associated with the belief that $p$ that the burden of demonstrating that we should think of them as believers of $p$ falls squarely with those who wish to defend doxasticism. Their answers to the first two, and most substantive, objections in this group appeal to non-standard aspects of the delusional person's situation that they claim satisfactorily excuse (in the above-discussed, semi-technical sense) the occasional absence of manifestations relevant to the stereotypical dispositions expected to compose the profile.

\section{Theoretical reason, revisited}

The first non-standard features appealed to by Bayne and Pacherie are the unusual perceptual and affective experiences of deluded subjects, and they are invoked to meet the objection from theoretical reason. It should be noted that this answer depends on a bottom-up explanation of delusions. If, as bottom-up theorists claim, monothematic delusions are grounded in unusual experiences, then, they claim, 'these conditions may be thought to excuse the patient from manifesting the cognitive dispositions stereotypically associated with their belief' (2005, p.184). Bayne and Pacherie illustrate this with the case of the Capgras delusion, for which there are strong bottom-up explanations (Bayne and Pacherie 2004; Pacherie 2009). The conclusion they extract from such accounts of Capgras is that the patients are manifesting the relevant cognitive dispositions, such as the inclination to test their delusion and consider evidence, and that their abnormal perceptual and affective experiences continually reinforce their delusional belief. But in order for this answer to add to the defense of doxasticism, distinct bottom-up accounts of all the other (monothematic) delusions must be developed. These accounts must show that the subjects of other monothematic delusions have perceptual abnormalities that precipitate their delusions, and also that those perceptual abnormalities cause the cognitive dispositions that are distinctive of belief.

Principia 19(3): 379-404 (2015). 
However, hypothesis evaluation and verification isn't something one can point to in every case. For instance, in the case of delusions of thought-insertion or alien control, which involve the belief that one doesn't have ownership, and is not in control of, one's own thoughts and the actions that may emanate thereof (Pacherie, Green and Bayne 2006). While the hypothesis that someone is putting thoughts into one's head is antecedently highly implausible in the context of normal conceptions of causation, Bayne and Pacherie claim that the abnormal experience of agency to which some delusional persons are subjected precludes them from having normal ideas about causation and probability. The hypothesis of thought-insertion may then be formed to make sense of the anomaly, and given that there seemingly is no way to gather evidence for or against such a hypothesis, Bayne and Pacherie claim that its maintenance is understandable. They suggest that we are entitled to assume that the dispositions relevant for the delusional belief are not only present, but also being manifested (though, puzzlingly enough, this cannot be observed).

If such unusual conceptions of causation are at play-seeing that the subject fails to give up her aberrant state via the consideration of its extraordinary implausibilitythen what entitles us to assume that her deviations are excusable? This question is rendered irrelevant by the recognition that the two arguments based on the nonstandard features presented by Bayne and Pacherie actually aren't aimed at providing excuses at all. As Tumulty observes, 'They aim to show that we have failed to see subjects' activities as manifestations of those dispositions' (2011, p.606).

\section{Practical reason, revisited}

The third feature Bayne and Pacherie discuss is disrupted motivation, and it is invoked to answer the objection from practical reason. That is, it is meant to explain why deluded subjects don't manifest the behavioral dispositions (relevant to belief in the delusional content) that they may nevertheless have. Before discussing motivation, however, they remind proponents of the objection that, as psychiatrists know all too well, delusion-generated action is not as rare as is often thought. Indeed, Cotard patients often become akinetic and stop everyday activities like eating and washing (Young and Leafhead 1996). Patients suffering from delusions of guilt or self-accusation, sometimes as a consequence of psychotic depression, often engage in physical self-punishment and many attempt suicide (Miller and Chabrier 1988). Patients of de Clérambault's syndrome-as a consequence of falsely believing that another person is secretely in love with them-write letters, make phone calls, send gifts, pay visits, and in a number of cases become violent toward the unwitting object of their obsession (Berrios and Kennedy 2002). The list could go on indefinitely, since it simply isn't true that delusional subjects are always inert with respect to the delusional content (Bortolotti 2010, p.162-7).

Principia 19(3): 379-404 (2015). 
Nevertheless, as we have seen, there are many cases in which delusions don't cause people to act in the expected ways. In the idiom of dispositionalism: the absence of appropriate behavioral responses challenges belief-ascription. To account for these localized absences of behavioral manifestations, Bayne and Pacherie point out that action is not caused by cognitive states alone but by cognitive states in conjunction with motivational states, and that the motivation to act may not be acquired or not sustained in some cases. Bortolotti and Broome (2012) argue that this may be due to avolition, to emotional disturbances, or to the fact that, given the peculiar content of some delusions, the surrounding environment does not support the agent's motivation to act. Moreover, among the causes for disrupted motivation may also be the very content of a patient's delusion. Some contents, such as 'there is a nuclear power station inside my body' (David 1990), may not be conducive to any appropriate course of action.

These causes are reflected in Bayne's and Pacherie's example of choice, which is that of deluded patients who know that acting on their beliefs might result in hospitalization (Stone and Young 1997). As a consequence, they keep from acting in the way the dispositional profiles for the relevant delusional beliefs would lead us to expect. As Tumulty (2011, p.607) observes, such distinctive belief-desire pairs can function successfully as excuses, explaining why a subject fails to manifest a disposition without undermining the idea that she has the disposition. Indeed, to a lesser extent than delusional subjects, normal subjects also act in ways which are inconsistent with some of their reported beliefs (e.g., when they are hypocritical), as well as fail to act on some of their beliefs for lack of motivation (e.g., when they are weak-willed). The problem is that to decisively answer the objection from agency, Bayne and Pacherie need some account of those subjects who don't have distinctive belief-desire pairs to rationalize their behavior (or lack thereof).

One way to approach this would be to claim that since those subjects have generally disrupted motivation, they fail to act in the relevant way. However, regarding such a lack of motivation as sufficient to explain all of a subject's failures to manifest relevant behavioral dispositions would also open the possibility that the dispositions aren't there at all. That is, it would open the possibility that if the subject fails to act on her delusion it is because he does not fully believe the content of her delusion. In this spirit, Tumulty argues that in some cases, in which subjects fail to manifest the behavioral dispositions in the profile for belief (e.g. that their spouse has been abducted), the explanation is simply that the subject lacks these dispositions. This in turn is due to a persistent, if not permanent, lack of other relevant cognitive and phenomenal dispositions, which indicates that the subject falls short of full-fledged belief.

Principia 19(3): 379-404 (2015). 


\section{Lack of appropriate affect, revisited}

Finally, Bayne's and Pacherie's answer to the last objection presented earlier ('Lack of appropriate affect') doesn't appeal to any non-standard features. They concede that many deluded subjects have deviant emotional and affective responses to the contents of their delusions (for example, some Capgras sufferers are unconcerned about the supposed impostor in their homes). They don't attempt to excuse this deviance but instead resist the thought that emotional and affective dispositions are constitutive elements of the belief stereotype. They also observe that the ascription of emotional states is far from straightforward, since the subjective experience of emotion can dissociate from the behavioral features of emotion-some depressive patients, for instance, have the former but not the latter (Bentall 2003, p.225). Given the connection between some forms of delusion and depression, Bayne and Pacherie assert that some delusional patients may also have subjective experiences associated with certain emotions even when they lack the appropriate manifestations. 'If so, the question of whether such individuals have a certain emotion might not admit of a definitive answer' (2005, p.184).

Although Schwitzgebel states that the dispositional profiles for some beliefs will include dispositions to be in certain emotional states, Bayne and Pacherie are, of course, free to endorse a version of dispositionalism in which some beliefs which would normally be accompanied by a particular emotional state should be present in the absence of that state, as Tumulty points out (2011, p.20). However, doing so raises a new problem, namely, that reducing the number of dispositions in a profile increases the importance of the remaining dispositions. Suppose (for the sake of the argument) that the dispositional profile for a particular belief is taken to contain five dispositions. That means that a person who is missing one of them has four chances to match the profile in other ways, and hence other people have four dispositions to point to in assessing whether or not the person fits the profile. Now suppose that the dispositional profile for a particular belief is taken to contain only three dispositions. Now a person who is missing one of them has only two chances to match the profile in other ways.

Tumulty's concern about Bayne's and Pacherie's claim that emotional dispositions never count as essential to any profile for belief, then, is that it leaves would-be believers with fewer dispositions in their respective profiles. That raises the probability, with each disposition they lack, that that lack will be the one that tips them over into no longer counting as believers of the relevant proposition (since they are no longer meeting the key portions of the profile). Given that the delusion-prone population has a lot of trouble matching profiles, giving them fewer chances to do so consists in a doubtful move. While their failure to have the 'right' emotion no longer counts against them, their failure to (say) have an appropriate disposition to action counts 
against them more than it otherwise would. Furthermore, putting more weight on other kinds of dispositions is problematic because delusional subjects don't necessarily do a better job at maintaining those dispositions. Hence, removing the expectation that delusional subjects manifest the relevant emotions dispositions does not make it easier to count them as believers.

\section{Conclusion}

Tumulty's careful consideration of the features to which Bayne and Pacherie call attention-abnormal perceptual experiences, abnormal experiences of agency, and disrupted motivation-shows that appealing to these features does not really help us reach the conclusion at which they aimed to arrive, namely, that most delusional subjects in fact have the belief-relevant dispositions they apparently fail to manifest. As far as I can see, Tumulty's results point to a disjunction: we must opt either for doxasticism, or for dispositionalism about delusions. Of course, if one were to opt for defending doxasticism, answers to the usual objections would have to be devised without Bayne's and Pacherie's appeal to dispositionalism. An industrious attempt at such an undertaking has been recently presented by Bortolotti (2010). She does not, however, present us with good enough reasons to discard the kind of approach that has been the center of this investigation.

At first, Bortolotti (2010, p.20-1) dismisses what she terms the 'sliding scale' approach on the questionable grounds that such an approach, by not giving a straightforward answer to the question 'Does the patient believe that $p$ ?', is unable to characterize precisely whether the patient's actions are intentional, which complicates issues of ethical and policy-guiding import. However, as Schwitzgebel rightly recognizes, apart from that not being nearly enough reason to discard an approach without more ado, its proponents might just as well suggest that in many cases of delusion it shouldn't be straightforward to assess intentionality, and that the ethical and policy applications are complicated, so that a philosophical approach that renders these matters straightforward is misleadingly simplistic' (2012, p.15). Ironically, toward the end of her book, Bortolotti hints at the in-between approach we have been discussing when she writes:

Rarely do we have these clear-cut cases ... Most of the delusions we read about, and we come across, are integrated in the subject's narrative, to some extent, and with limitations. They may be excessively compartmentalized, for instance, or justified tentatively. That is what makes it so difficult to discuss the relationship between delusions, subjects' commitment to the content of the delusion, and autonomy. As authorship comes in degrees, so does the capacity to manifest the endorsement of the delusional thought in autonomous thought and action. (2010, p.252)

Principia 19(3): 379-404 (2015). 
As Schwitzgebel observes, from the fact that Bortolotti (2010, p.242) regards authorship and endorsement as necessary for belief, it seems to follow that in the quoted passage she is acknowledging that many actual delusions are in-between cases of belief. This wavering on Bortolotti's part is symptomatic of an increasingly widespread, if latent, perception of which a recent formulation can be found in Bayne's assertion that 'there may not be enough determinacy in our ordinary conception of belief for there to be a fact of the matter as to whether many belief-like states are really beliefs or not' (2010, p.332). I would like to conclude this inquiry with a few additional points in favor of pursuing a sliding scale approach along the lines of what may have been originally contemplated by Bayne and Pacherie, but this time definitively forfeiting the ambition to ascribe doxastic status to 'most' delusional states-a methodological approach to which it seems Bayne himself may now be open, and which is suggested both by the recognition that delusions resist unqualified ascription of doxastic status, and by the preceding analysis of the failed attempt at vindicating doxasticism by resorting to dispositionalism.

I want to claim that the difficulties I have surveyed concerning the ascription of belief to delusional subjects are not due to our limited epistemic perspective-by which I consciously imply that whatever indeterminacy we face in our attempts is an indeterminacy inherent in our folk psychology. This claim concerns the nature of the folk-psychological notion of belief and the limits of its application. The underlying assumption in almost all discussions of the doxastic status of borderline phenomena (including self-deception, implicit bias, etc.) is that somehow there are necessary and sufficient conditions for the application of the concept of belief, such that any given mental state can be determinately classified as either being, or failing to be, a belief. Such an assumption seems groundless for the simple reason that 'belief' is a vague concept. Undoubtedly it is a helpful tool in predicting and explaining behavior in ordinary circumstances, which happens when all (or most of) the plausible candidates for assessing its presence converge on the same result-or in dispositionalist terms, when the belief-relevant dispositions are manifested. However, this does not mean that there is always a fact of the matter as to whether a subject believes a given proposition. The appropriate response when ascription breaks down, and when persistent disagreement over how to describe a certain kind of mental state arises, is to recognize that no single set of rules is privileged by our ordinary (folk) practices.

I am aware that such an answer may seem unhelpful, and I agree that it should be accompanied by a positive lesson and a direction for future research, in keeping with the goal of attaining a better understanding of delusions and other puzzling phenomena. It is not easy to rest content with a conclusion such as that 'there is a proposition concerning which there is evidence that the subject believes it, and evidence that they do not, and that is the best that can be said' (Hamilton 2007, p.231). Indeed, we can be more informative than that. In order to adequately characterize the 
cognitive states of delusional and other deeply conflicted subjects, we should (in the appropriate contexts) abandon the idea that simple folk-psychological abstractions should frame research into complex and variegated psychological and psychiatric conditions and, rather, descend to lower levels of explanation, namely, to the various neurobiological and cognitive processes that make up the profile of the subjects in the grasp of the relevant phenomenon. This chimes with Schwitzgebel's aforementioned suggestion that we should treat 'belief' as a vague predicate and, when confronted with difficulties of ascription stemming from its vagueness, we should turn to providing as much further detail as we may be able to come up with. This will not be achieved by looking for precision where it cannot be found.

So my conclusion is not quite that, say, the Capgras patient doesn't believe that her loved one has been replaced by a double, or that the Cotard patient doesn't believe that she is dead. Rather, it is that the question as to whether these subjects believe the content of their delusions cannot be answered with a plain 'yes' or 'no' - which doesn't mean we should give up our efforts to understand delusion, but that we should shift our attention to what we can do. In this, I enthusiastically agree with Graham that since 'delusions [are] messy, compound, and complex psychological states or attitudes (thoughts, feelings, and so on), defined more by how persons mismanage their content and fail to prudently act in terms of them, than by qualifying as beliefs,' a realistic picture of delusion 'should leave room for the clinical vagaries of delusional presentation and not try to funnel each case of delusion through the taxonomic filter of the propositional attitude of belief' (2010b, p.337). The prolonged debate over how to characterize delusional states is predominantly due to participants using folkpsychological tools that simply can't handle the task.

\section{Acknowledgments}

The author kindly thanks Paulo Faria, Eros Carvalho, George Graham, and an anonymous referee for helpful comments on earlier drafts of this paper.

\section{References}

American Psychiatric Association. 2013. Diagnostic and Statistical Manual of Mental Disorders. Fifth edition. American Psychiatric Association.

Bayne, T. 2010. Delusions as Doxastic States: Contexts, Compartments, and Commitments. Philosophy, Psychiatry, \& Psychology 17(4): 329-36.

Bortolotti, L.; Broome, M. R. 2012. Affective dimensions of the phenomenon of double bookkeeping in delusions. Emotion Review 4(2): 187-91.

Bayne, T.; Pacherie, E. 2004. Bottom-up or top-down: Campbell's rationalist account of monothematic delusions. Philosophy, Psychiatry \& Psychology 11(1): 1-11.

- 2005. In Defence of the Doxastic Conception of Delusions. Mind \& Language 20(2): $163-88$.

Principia 19(3): 379-404 (2015). 
Bentall, R. 2003. Madness Explained: Psychosis and Human Nature. Allen Lane.

Bermudez, J. L. 2001. Normativity and rationality in delusional psychiatric disorders. Mind \& Language 16(5): 457-93.

Berrios, G. E. 1991. Delusions as 'wrong beliefs': A conceptual history. British Journal of Psychiatry 159: 6-13.

- 1996. The History of Mental Symptoms. Cambridge University Press.

Berrios, G. E.; Kennedy, N. 2002. Erotomania: a conceptual history. History of Psychiatry 13: 381-400.

Bleuler, E. 1916[1924]. Textbook of Psychiatry. 4th ed. Trans. A.A. Brill. Macmillan.

Bortolotti, L. 2004. Can we interpret irrational behavior? Behavior and Philosophy 32(2): 359-75.

- 2005. Delusions and the background of rationality. Mind \& Language 20(2): 189-208.

- 2010. Delusions and Other Irrational Beliefs. Oxford University Press.

Campbell, J. 2001. Rationality, meaning, and the analysis of delusion. Philosophy, Psychiatry, \& Psychology 8(2/3): 89-100.

Chadwick, P.; Brichwood M.; Trower, P. 1996. Cognitive Therapy for Delusions, Voices and Paranoia. Wiley.

Cherniak, C. 1986. Minimal Rationality. MIT Press.

Currie, G. 2000. Imagination, delusion and hallucinations. In: M. Coltheart; M. Davies (eds.) Pathologies of Belief. Blackwell.

Currie, G.; Ravenscroft, I. 2002. Recreative Minds: Imagination in Philosophy and Psychology. Oxford University Press.

David, A. 1990. Insight and psychosis. British Journal of Psychiatry 156: 798-808.

Davidson, D. 1974. Psychology as philosophy. In: S. C. Brown (ed.) Philosophy of Psychology. Macmillan.

Davies, M.; Coltheart, M. 2000. Introduction: Pathologies of Belief. In: M. Coltheart; M. Davies (eds.) Pathologies of Belief. Blackwell.

Davies, M.; Coltheart, M.; Langdon, R.; Breen, N. 2001. Monothematic delusions: Towards a two-factor account. Philosophy, Psychiatry \& Psychology 8(2/3): 133-58.

De Pauw, K. W.; Szulecka, T. K. 1988. Dangerous delusions: Violence and the misidentification syndromes. British Journal of Psychiatry 152: 91-6.

Dennett, D. 1987. Making sense of ourselves. In: The Intentional Stance. MIT Press.

Dickerson, F. B. 2000. Cognitive behavioural psychotherapy for schizophrenia: A review of recent empirical studies. Schizophrenia Research 43(2/3): 71-90.

Egan, A. 2009. Imagination, delusion, and self-deception. In: T. Bayne; J. Fernandez (eds.) Delusion and Self-Deception: Affective and Motivational Influences on Belief Formation. Psychology Press.

Fodor, J. A. 1983. The Modularity of Mind. MIT Press.

Gendler, T. S. 2007. Self-deception as pretense. Philosophical Perspectives 21: 231-58.

Gerrans, P. 2001. Authorship and ownership of thoughts. Philosophy, Psychiatry \& Psychology 8(2/3): 231-7.

Goodman, N. 1983. Fact, Fiction, and Forecast. Harvard University Press.

Hamilton, A. 2007. Against the belief model of delusion. In: M. C. Chung; K. W. M. Fulford; G. Graham (eds.) Reconceiving Schizophrenia. Oxford University Press. 
Jaspers, K. 1913[1963]. General Psychopathology. Trans. J. Hoenig and M. W. Hamilton. Manchester University Press.

Kripke, S. 1980. Naming and Necessity. Harvard University Press.

Kunda, Z. 1990. The case for motivated reasoning. Psychological Bulletin 108(3): 480-98.

Miller, F. T.; Chabrier, L. A. 1988. Suicide attempts correlate with delusional content in major depression. Psychopathology 21(1): 34-7.

Nisbett, R.; Ross, L. 1980. Human Inference. Prentice-Hall.

Pacherie, E. 2009. Perception, emotion, and delusions: The case of the Capgras delusion. In: T. Bayne; J. Fernandez (eds.) Delusion and Self-Deception: Affective and Motivational Influences on Belief Formation. Psychology Press.

Pacherie, E.; Green, M.; Bayne, T. 2006. Phenomenology and delusions: Who put the 'alien' in alien control? Consciousness and Cognition 15: 566-77.

Price, H. H. 1960[1969]. Belief. George Allen and Unwin.

Putnam, H. 1975. The meaning of 'meaning'. Minnesota Studies in the Philosophy of Science 7: 131-93.

Quine, W. V.; Ullian, J. 1970. The Web of Belief. Random House.

Ryle, G. 1949. The Concept of Mind. Hutchinson.

Sass, L. 1994. The Paradoxes of Delusion: Wittgenstein, Schreber, and the Schizophrenic Mind. Cornell University Press.

Schwitzgebel, E. 2001. In-between believing. The Philosophical Quarterly 51: 76-82.

- 2002. A phenomenal, dispositional account of belief. Noûs 36(2): 249-75.

- 2012. Mad belief. Neuroethics 5(1): 13-17.

Stephens, G. L.; Graham, G. 2004. Reconceiving delusions. International Review of Psychiatry 16(3): 236-41.

Stone, T.; Young, A. W. 1997. Delusions and brain injury: the philosophy and psychology of belief. Mind \& Language 12: 327-364.

Tumulty, M. 2011. Delusions and Dispositionalism about Belief. Mind \& Language 26(5): 596-628.

Velleman, J. D. 2000. On the Aim of Belief. In: The Possibility of Practical Reason. Oxford University Press.

Wang, E. W. 2014. Perdition Days: On Experiencing Psychosis. The Toast. URL = http://thetoast.net/2014/06/25/perdition-days-experiencing-psychosis/ Retrieved on September 10, 2014.

Weinstein, E. A.; Kahn, R. L. 1955. Denial of Illness. Charles C. Thomas.

Young, A. W. 1999. Delusions. The Monist 82(4): 571-89.

- 2000. Wondrous strange: The neuropsychology of abnormal beliefs. In: M. Coltheart; M. Davies (eds.) Pathologies of Belief. Blackwell.

Young, A. W.; Leafhead, K. 1996. Betwixt life and death: Case studies of the Cotard delusion. In: P. Halligan; J. Marshall (eds.) Method in Madness. Psychology Press.

JosÉ EDUARDo PORCHER Post-Doctoral Fellow (PNPD/CAPES)

Universidade Federal do Paraná

BRASIL

jeporcher@gmail.com

Principia 19(3): 379-404 (2015). 


\section{Notes}

${ }^{1}$ In listing these objections I largely follow the excellent survey provided by Bayne and Pacherie (2005), as well as the discussion of problematic features of delusion by Stephens and Graham (2004), Egan (2009) and Bortolotti (2010).

2 I say 'appropriate' rather than 'necessary' because circumscribed (insulated) "beliefs" will usually stand in a number of (nonlogical) connections to the subject's other mental states: that of being simultaneously held to begin with, and then that of causing or being caused by other mental states.

${ }^{3}$ It must be noted, however, that on Putnam's account these are not just properties 'we are apt to associate' with a tiger - they are criteria of tigerhood. Putnam's concept of a stereotype, in other words, is an epistemological one: a stereotype is the set of properties we use to identify something as an F, and it is to be sharply distinguished both from the (psychological) notion of 'what we are apt to associate' with an F and from the (metaphysical) notion of what makes an $\mathrm{F}$ an $\mathrm{F}$. So the stereotype of water is: 'insipid, odorless, etc. liquid which quenches thirst, is found in lakes, rivers etc.' Yet that is not what water is: water is a chemical substance with the formula $\mathrm{H}_{2} \mathrm{O}$. See also Lecture III in Kripke (1980).

${ }^{4}$ Although grammatically in the indicative mood, I suspect a subjunctive conditional is what is meant here (as betrayed in the surface grammar by the use of 'will', implying necessity), namely: 'If condition $\mathrm{C}$ were to hold, the object $\mathrm{O}$ would (be likely to) enter (or remain) in state S'. The latter sentence states explicitly that there is a nomic connection between being in condition $\mathrm{C}$ and entering (or remaining) in state $\mathrm{S}$, something which no strictly indicative conditional would have the force to express ('If P then Q' iff 'Not-P and/or Q': no law to be found there). For a classic discussion, see the first chapter in Goodman (1983).

${ }^{5}$ It must be noted, however, that the strength of Davidson's and Dennett's constraint isn't the same. While Davidson leaves room for further inquiry by postulating the need for 'a large degree of rationality', Dennett's constraint seems impervious to qualification. Though a very interesting debate in itself, I must leave the tenability of rationality constraints on beliefascription aside for reasons of space and scope. But see Bortolotti (2004; 2005).

Principia 19(3): 379-404 (2015). 